\title{
Qualitative analysis of an ethanolic extract from Trametes versicolor and biological screening against Leishmania amazonensis
}

\author{
Vivian Leliebre-Lara ${ }^{1}$, Marley García ${ }^{2}$, Clara Nogueiras ${ }^{1}$, Lianet Monzote ${ }^{2^{*}}$ \\ ${ }^{1}$ Centre for Natural Product Studies, Faculty of Chemistry, University of Havana, Cuba; ${ }^{2}$ Parasitology Department, Institute of Tropical Medicine \\ "Pedro Kouri", Havana, Cuba
}

\section{A B S TR A C T}

\begin{abstract}
This study was carried out with basidiomycete mushroom Trametes versicolor. The fruiting body of the mentioned mushroom was extracted with alcohol and submitted to a qualitative phytochemical screening for secondary metabolites identification. This experiment afforded the presence of secondary metabolites kind of triterpenes, steroids, flavonoids, alkaloids, and in a small amount cardenolides. Quinones were not found within tested metabolites. In addition, extracts of this mushroom fresh fruiting body of different polarity (ranging from $n$-hexane, dichloromethane, ethyl acetate until ethanol) were evaluated against promastigotes of Leishmania amazonensis, a widespread tropical and subtropical disease produced by around 20 species of protozoa from Leishmania genus. The ethyl acetate and the ethanol extract exhibited anti-leishmanial activity, with $\mathrm{IC}_{50}$ values of $101.8 \pm 4.2 \mu \mathrm{g} / \mathrm{mL}$ and $97.4 \pm 2.0 \mu \mathrm{g} / \mathrm{mL}$, respectively. The cytotoxicity against peritoneal macrophage from BALB/c mice from those extracts was reported.
\end{abstract}

Keywords: Trametes versicolor; Leishmania amazonensis; Metabolites

\section{INTRODUCTION}

Along the history men have used mushrooms not only for its own diet but also for the treatment of numerous diseases. From several mushroom species have been isolated more than hundred compounds with remarkable growth inhibition activity against different kind of tumors. The antitumor activity of these substances has captured the attention of the scientific community. Nevertheless most of the mushroom naturally occurring constituents haven't been characterized. Basidiomycetes are considered as a rich source of pharmacologically active substances which exhibit a wide range of biological activities such as antimicrobial Suay et al., (2000), antiviral Tochikura et al. (1987); (1989), antifungal Nakajima et al., (1976), anticancer Kobayashi et al., (1994), antioxidant Yun et al., (2002), nematocidal Morrison et al., (2002) and other activities (Stamets et al., 2001). Recently, was report the biological evaluation of over 200 mushroom species from these, more than $75 \%$ of screened basidiomycetes showed strong antimicrobial activity (Suay et al., 2000). The activity was associated not only with small molecules but also with high molecular weight cell wall polysaccharides. The main topic during seeking for antimicrobial compounds from basidiomycetes is based on the statement that humans as well as animals share common microbial pathogens with fungi, such as Escherichia coli, Staphylococcus aureus, and Pseudomonas aeruginosa, so we can benefit from defensive strategies used by fungi against microorganisms (Sheena et al., 2003).

Trametes versicolor (Bres. Rivarden) is probably the most studied and biologically evaluated of all medicinal basidiomycetes mushrooms according to anticancer effects. However, those studies had been exclusively focus on two polysaccharides-Krestin PSK and polysaccharide peptide (PSP), these are heteroglucans with $\alpha-(1-4)$ and $b$-(1-3) glucosidic bonds, with a protein or polypeptide component Okada and Minamishima, (1987); Colins, 1997). What makes these polysaccharides attractive is their immunomodulatory activity, which provides potent antitumor effects (Wasser and Weis, (1999); 1999 b).

\footnotetext{
${ }^{*}$ Corresponding author:

Lianet Monzote, Departamento de Parasitología, Instituto de Medicina Tropical "Pedro Kouri", Apartado Postal 601, Marianao 13, Ciudad de la Habana, Cuba. Tel: +53 7202 5061. Fax: +53 7204 6051. E-mail: monzote@ipk.sld.cu
} 
Leishmaniasis is a widespread tropical and subtropical disease produced by around 20 species of protozoa from Leishmania genus and it is transmitted by insects. Domestic and wild animals such as dogs, fox, rabbits and small mammals are the reservoirs. This parasite invades different organs from some mammals, produce harsh injuries even death. Nowadays, there is no cure for it despite many substances isolated from plants and chemicals were used to fight against this infection, this attempt has failed due to the highest drugs toxicity and parasite resistance (Sundar, 2001). The search for better drugs, effective, with lower toxicity is every time needed meanwhile, this illness is increasing the number of infecting people in more than 1.5 million annually. Natural products may offer a promising source of chemical diversity for identification of new drugs. In the present work, the evaluation of antileishmanial activity of $T$. versicolor extracts of different polarity and the result of a preliminary phytochemical screening of the ethanol crude extract from the mentioned mushroom are reported.

\section{MATERIALS AND METHODS}

\section{Mushroom material}

T. versicolor fruiting body was collected in November of 2003, from a dead and dry trunk, at Turquinos's National Park Santiago de Cuba, Cuba. The botanical identification was accomplished by the Mycology Department at the Systematic and Ecology Institute in Havana, Cuba according to the described method by Decock (Decock and Herrera, 2000). A voucher specimen No. 9805 was deposited at the Herbarium of the Cuban Botanical Garden in Havana. The mushroom was collected following recommendation by Stamets (Stamets and Chilton, 1983) and conserved trough the method of Burdsall (Burdsall et al., 1994).

\section{Extract preparation}

T. versicolor fruiting body (250 g) was dried, milled and subjected to a solid-liquid extraction (maceration and ethanol decoction) in the dark at room temperature for a week, subsequently with four solvents of increasing polarity. The last ethanol extract was obtained by decoction of the milled material during an hour under ethanol refluxed. The four extraction steps yielded $0.42 \mathrm{~g}$ of $n$-hexane extract, $0.97 \mathrm{~g}$ of $\mathrm{CH}_{2} \mathrm{Cl}_{2}$ extract, $0.31 \mathrm{~g}$ of EtOAc extract, $1.06 \mathrm{~g}$ and $1.3 \mathrm{~g}$ of EtOH extract obtained by maceration and $0.78 \mathrm{~g}$ from EtOH extract obtained by decoction. The organic solvent extracts were separately concentrated in vacuum using rotatory evaporator at $35 \pm 2^{\circ} \mathrm{C}$ Büchi, Germany.

\section{Phytochemical screening}

Virgin mushroom material $(5 \mathrm{~g})$ was extracted with ethanol under the same conditions above described; this extract was used on the qualitative analysis for secondary metabolites detection using Rondina and Cossio method (Rondina and Coussio, 1969).

\section{Parasites}

L. amazonensis (MHOM/77BR/LTB0016) was kindly provided by the Department of Immunology, Oswaldo Cruz Foundation (FIOCRUZ), Brazil. Parasites were routinely isolated from mouse lesions and maintained as promastigotes at $26^{\circ} \mathrm{C}$ in Schneider's medium (SIGMA, St. Louis, MO, USA) containing 10\% heat-inactivated fetal bovine serum (HFBS) (SIGMA, St. Louis, MO, USA), $100 \mathrm{mg}$ of streptomycin/mL, and $100 \mathrm{U}$ of penicillin/mL.

\section{Antileishmanial assay}

Exponentially growing cells $\left(10^{5}\right.$ promastigotes $/ \mathrm{mL}$, $199 \mathrm{~mL}$ ) were distributed in 96-well plates. One microliter of extracts or $1 \mathrm{~mL}$ of DMSO for control was added to well-plates at a final concentration between 12.5 and $200 \mu \mathrm{g} / \mathrm{mL}$, and then incubated at $26^{\circ} \mathrm{C}$ for $72 \mathrm{~h}$. After 3 days of exposure, the parasites were incubated for $3 \mathrm{~h}$ with p-nitrophenol phosphate $(20 \mathrm{mg} / \mathrm{ml})$ dissolved in $1 \mathrm{M}$ sodium acetate buffer (BDH, Poole, England), $\mathrm{pH}$ 5.5, with 1\% Triton X-100 (BDH, Poole, England) at $37^{\circ} \mathrm{C}$. The absorbance was determined in an EMS Reader MF Version 2.4-0, at a wavelength of $405 \mathrm{~nm}$. The 50\% inhibitory concentration $\left(\mathrm{IC}_{50}\right)$ was obtained from doseresponse curves fit to data by means of the equation for the sigmoidal $\mathrm{E}_{\max }$ model (Bodley et al., 1995).

\section{Cytotoxicity assay}

Resident macrophages were collected from peritoneal cavities of normal BALB/c mice in ice-cold RPMI 1640 medium (SIGMA, St. Louis, Mo, USA), supplemented with antibiotics, seeded at 30,000 cells/well and allowed to adhere for $2 \mathrm{~h}$ at $37^{\circ} \mathrm{C}$ in $5 \% \mathrm{CO}_{2}$. After non-adherent cells were removed by washing with PBS, dilutions of the extracts, in $1 \mu \mathrm{L}$ of DMSO, were added in $200 \mu \mathrm{L}$ of medium with $10 \%$ HFBS and antibiotics. The macrophages were treated with six concentrations of the product and cultures treated with $1 \mu \mathrm{L}$ of DMSO were included as controls. The cytotoxicity was determined after 3 days of incubation using the colorimetric assay with 3-[4,5-dimethylthiazol-2-yl]-2,5diphenyltetrazolium bromide (MTT) (SIGMA, St. Louis, MO, USA). MTT solutions were prepared at $5 \mathrm{mg} / \mathrm{mL}$ in PBS, filtered and sterilized at the time of use and $15 \mu \mathrm{L}$ of each solution were added to each well. After incubation for an additional $4 \mathrm{~h}$, the formazan crystals were dissolved by addition of $100 \mu \mathrm{L}$ of DMSO. The optical density was determined using an EMS Reader MF Version 2.4-0 at a test wavelength of $560 \mathrm{~nm}$ and a reference wavelength of $630 \mathrm{~nm}$ (Sladowski et al., 1993). The $50 \%$ cytotoxic concentration $\left(\mathrm{CC}_{50}\right)$ was obtained from dose-response 
curves fit to data by means of the equation for the sigmoidal $\mathrm{E}_{\max }$ model (Bodley et al., 1995).

Selectivity indices (SI) were then calculated by dividing the $\mathrm{CC}_{50}$ for peritoneal macrophages of $\mathrm{BALB} / \mathrm{c}$ mice by the $\mathrm{IC}_{50}$ for Leishmania promastigotes (Tiuman et al., 2005).

\section{RESULTS}

\section{Phytochemical screening}

The phytochemical screening revealed a complex and rich mixture of different metabolites family (Table 1). In particular, triterpenes, steroids, flavonoids and alcaloids were demonstrated.

\section{Antileishmanial screening}

The samples of different polarity of $T$. versicolor were tested against promastigotes of $L$. amazonensis. Promastigotes are not the infective form of the parasite for vertebrate host; it is the most effective culture for the screening on leismanicidal activity due to its reproducibility, quick and easy implementation. All the extracts displayed antileishmanial activity of $50 \%$ at concentrations up to $100 \mu \mathrm{g} / \mathrm{mL}$; however ethyl acetate and the ethanol extract (I) exhibited the same percent of growth inhibition at lower concentration (Table 2).

\section{DISCUSSION}

The qualitative phytochemical screening of ethanol crude extract from $T$. versicolor was accomplished using the

Table 1: Qualitative phytochemical screening of ethanol crude
extract from Trametes versicolor
\begin{tabular}{lc}
\hline Metabolites assayed & Results \\
\hline Triterpenes \& steroids & +++ \\
Amine compounds & ++ \\
Flavonoids & +++ \\
Alcaloids & +++ \\
Quinones & - \\
Cardenolides & + \\
\hline
\end{tabular}

(-): Not detectable, (+): Scarcely, (++): Moderate, (+++): Plentiful

Table 2: Antileishmanial activity $\left(\mathrm{IC}_{50}\right)$, cytotoxicity $\left(\mathrm{CC}_{50}\right)$ and selectivity (SI) of Trametes versicolor extracts

\begin{tabular}{lccc}
\hline Extracts & $\mathrm{IC}_{50}{ }^{\mathrm{a}}(\mu \mathrm{g} / \mathrm{mL}) \pm \mathrm{SD}^{\mathrm{b}}$ & $\mathrm{CC}_{50}{ }^{\mathrm{c}}(\mu \mathrm{g} / \mathrm{mL}) \pm \mathrm{SD}^{\mathrm{b}}$ & $\mathbf{S I}^{\mathrm{d}}$ \\
\hline TV- 1 (n-hexane) & $290.7 \pm 4.5$ & - & - \\
TV-2 (CH2Cl2) & $293.8 \pm 1.3$ & - & - \\
TV-3 (EtOAc) & $101.8 \pm 4.2$ & $187.1 \pm 2.8$ & 2 \\
TV-4 (EtOH I) & $97.4 \pm 2.0$ & $98.0 \pm 6.4$ & 1 \\
TV-5 (EtOH II) & $129.7 \pm 1.1$ & - & - \\
TV-6 (EtOH III) & $120.3 \pm 3.1$ & - & - \\
\hline
\end{tabular}

$\mathrm{IC}_{50}{ }^{\mathrm{a}}$ : Extract concentration that cause $50 \%$ of growth inhibition,

$\mathrm{SD}^{\mathrm{b}}$ : Standard deviation, $\mathrm{CC}_{50}{ }^{\mathrm{c}}$ : Extract concentration that cause $50 \%$ of mortality, Sld: Selectivity index ( $\mathrm{CC}_{50}$ of macrophage/ $/ \mathrm{C}_{50}$ of promastigotes),

TV: Trametes versicolor extract method described by Rondina and Coussio (1969). This technique combines the metabolites solubility with the solvent polarity and $\mathrm{pH}$ variation during the extraction process. The crude is divided in fractions which are submitted to qualitative assays of color develop and/or solid precipitation depending on the type of metabolites. In our study, an intensive green color in LiebermanBurchard assays announced the presence of triterpenes and steroids; this color is associated to compounds with $\mathrm{B}$ and $\mathrm{C}$ unsaturated rings from this kind of polycyclic system. During alkaloids detection the corresponding fractions afforded a positive answer by a yellow solid precipitation after addition of three drops of Mayer reagent; a brownish solid appears during Wagner assay and there were no reaction under Hager reagent addition. The trametes fraction turned into yellow color the amilic alcohol layer during Shinoda assay which reveal metabolites kind of flavonoids such as flavonones, flavones, flavanonols, chalcones and flavonols. Ninhidrine addition to the respective fraction produced a slightly violet color indicating a possible presence of amine compounds.

Through Kedde reagent the fraction involved displayed a moderate violet color exposing the existence of a $\gamma$-lactonic- $\alpha, \beta$-insaturated group for cardenolides compound. Börntrager assay for quinones detection, were negative or not detected in the sample.

Related to antileishmanial screening, the result suggests that both extracts should possess the substance responsible for the antileishmanial activity. It is not totally discarded that a synergic effect between some metabolites of the extracts can produced this activity. The more active extracts were selected for the cytotoxicity evaluation on peritoneal macrophage from BALB/c mice; comparing their activity against Leishmania promastigotes and the cytotoxicity displayed against peritoneal macrophage which establish whether "in vitro" activity of the extracts it's owing to selective metabolites composition or to its cytotoxic activity (Chan-Bacab et al., (2001); Croft et al., 2006). Besides the ethanol extract was active to the lower concentration the extracts showed a high toxic effect indicating an unspecific action due to the small value of SI obtained. A further experiment with the fractions obtained from this extracts could be accomplished till the real responsible metabolite for his activity is founded.

There are some reports about the biological activity of the polar fractions of this mushroom, which contains cytotoxic, polyoxygenated ergosterol derivatives and polysaccharides with anticancer effects. (Valisolalao et al. (1983); Tochikura et al., (1987); (1989). Recently, the composition of $T$. versicolor acetone's extract with antioxidant and anti-inflammatory properties was reported. 
The more active fractions revealed presence of phenolic compounds, highly polihydroxylated substances and fatty acids (Masumi et al., 2013).

In conclusion, in our knowledge, this result constitutes the first report about the antileishmanial activity showed by extracts from $T$. versicolor. The activity displayed by this extracts warrants the study of their composition as a potential source of new agents against Leishmania. The obtained activity could have been due to the existence of polar compounds kind of flavonoids which most of the time appears in ethanol extracts. Further studies could be performing to evaluate the activity of its metabolites as antileishmanial drugs.

\section{Conflict of interest}

The authors declare that they have no conflict of interest.

\section{Author contributions}

V. L. and L. M. made the major contribution to paper. V. L. was involved in material collection, phytochemical assay and writes the article. L. M. carried out the antileishmanial assay, cytotoxicity screening and writes the article. M. G. contributed with antileishmanial assays. C. N. reviewed the manuscript and phytochemical experiments.

\section{REFERENCES}

Bodley, A. L., M. W. McGarry and T. A. Shapiro. 1995. Drug cytotoxicity assay for African Trypanosomes and Leishmania Species. J. Infect. Dis. 172: 1157-1159.

Burdsall, H. Jr. and E. B. Dorworth. 1994. Preserving cultures of wood-decaying basidiomycotina using sterile distilled water. Mycologia. 6: 275-280.

Colins, R. A. and T. B. Ng. 1997. Polysaccharopeptide from Coriolus versicolor has potential for use against human immunodeficiency virus type 1 infection. Life Sci. 60: PL383-PL387.

Croft, S., K. Seifert and V. Yardley. 2006. Current scenario of drug development for leishmaniasis. Indian J. Med. Res. 123: 399410.

Chan-Bacab, M. J. and L. M. Peña-Rodríguez. 2001. Plant natural products with leishmanicidal activity. Nat. Prod. Rep. 18: 674688.

Decock, C. and S. Herrera. 2000. Studies in Perenniporia. Navisporus ortizii, a synonym of Perenniporia martius and a note on Navisporus and Perenniporia in Cuba Cryptogamie. Mycologie. 21: 153-162.

Kobayashi, Y., K. Kariya, K. Saigenji and K. Nakamura. 1994. Enhancement of anti-cancer activity of Cisdiaminedi chloroplatinum by the protein-bound polysaccharide of Coriolus versicolor QUEL (PS-K) in vitro. Cancer Biother. 9: 351-358.

Masumi, K., H. Masahiro, U. Katsumi, K. Kazuo, O. Yuzuru and S. Takayuki. 2013. Antioxidant/anti-inflammatory activities and chemical composition of extracts from the mushroom Trametes versicolor. Int. J. Nutr. Food Sci. 2: 85-91.

Morrison, E., B. Kosiak, A. Ritieni, A. H. Aastveit, S. Uhlig and A. Bernhoft. 2002. Mycotoxin production by Fusariuma venaceum strains isolated from Norwegian grain and the cytotoxicity of rice culture extracts to porcine kidney epithelial cells. J. Agric. Food Chem. 50: 3070-3075.

Nakajima, S., K. Kawai, S. Yamada and Y. Sawai. 1976. Isolation of oospo lactone as antifungal principle of Gloeophyllum sepiarium. Agric. Biol. Chem. 40: 811-812.

Okada, M. and Y. Minamishima. 1987. The efficacy of biological response modifiers against murine cytomegalovirus infection in normal and immunodeficient mice. Microb. Immunol. 31: 45-57.

Rondina, R. V. and J. D. Coussio. 1969. Estudio fitoquímico de plantas Medicinales. Revista de Investigaciones Agropecuaria y Producción Vegetal, Argentina.

Sheena, N., T. A. Ajith, M. A. Thomas and K. K. Janardhanan. 2003. Antibacterial activity of three macrofungi, Ganoder malucidum, Navesporus floccose and Phellinus rimosus occurring in South India. Pharm. Biol. 41: 564-567.

Sladowski, D., S. J. Steer, R. H. Clothier and M. Balls. 1993. An improve MTT assay. J. Immunol. Methods. 157: 203-207.

Stamets, P. 2001. Novel anti-virals from mushrooms. Herbal Gram. 51: 24-27.

Stamets, P. and J. S Chilton. 1983. The Mushroom Cultivator. A Practical Guide to Growing Mushrooms at Home Agarikon Press, Olympia, WA, EE. UU.

Suay, I., F. Arenal, F. J. Asenio, A. Basilio, M. A. Cabello, M. T. Diez, J. B. García, A. González del Val, J. Gorrochategui, P. Hernández, F. Peláez and M. F. Vicente. 2000. Screening of basidiomycetes for antimicrobial activities. Antonie van Leeuwenhoek. 78: 129-139.

Sundar S. 2001. Drug resistance in Indian visceral leishmaniasis. Trop. Med. Int. Health. 6: 849-854.

Tiuman, T. S., T. Ueda-Nakamura, D. A. G. Cortez, B. P. Dias Filho, J. A. Morgado-Díaz, W. de Souza and C. V. Nakamura. 2005. Antileishmanial activity of parthenolide, a sesquiterpene lactone isolated from Tanacetum parthenium. Antimicrob. Agents Chemother. 49: 176-182.

Valisolalao, J., B. Luu and G. Ourisson. 1983. Steroides cytotoxiques de polyporus versicolor. Tetrahedron. 39: 2779-2785.

Wasser, S. P. and A. L. Weis. 1999. Medicinal properties of substances occurring in higher basidiomycetes mushrooms: Current perspectives (Review). Int. J. Med. Mushrooms. 1: 31-62.

Wasser, S. P. and A. L. Weis. 1999. Therapeutic effects of substances occurring in higher basidiomycetes mushrooms: A modern perspective. Crit. Rev. Immunol. 19: 65-96.

Yun, B. S., Y. Cho, I. K. Lee, S. M. Cho, T. H. Lee, I. D. Yoo. 2002. Sterins $A$ and $B$, new antioxidative compounds from Stereum hirsutum. J. Antibiot. 55: 208-210. 